\title{
A FORMA DA FALTA: O DESEJO NA FENOMENOLOGIA DO ESPÍRITO
}

\author{
MARCUS VINICIUS DA CONCEIÇÃO FELIZARDO ${ }^{1}$
}

Resumo: O presente artigo pretende investigar o conceito de desejo (begiarde) em um momento central da obra de Hegel: o capítulo IV da Fenomenologia do Espírito. Entendemos que esse conceito possui grande amplitude na obra do autor, dando ensejo a discussão sobre temas maiores de sua filosofia, como, por exemplo, as concepções de "reconhecimento” (anerkennung), “consciência-de-si” (selbstbewusstsein) e "espírito” (geist). Assim, partindo dos problemas que Hegel enxerga na modernidade filosófica, sobretudo na filosofia kantiana, o primeiro passo será a reconstrução do aparecimento do conceito de desejo e sua inserção em outras problemáticas da filosofia hegeliana apresentadas no capítulo, tendo sempre em vista a repercussão da questão na experiência intelec tual contemporânea.

Palavras-chave: Hegel; Desejo; Negatividade.

O abismo entre o ser-para-si e o ser-para-outrem, eis o escândalo que apavora. Ou que designa o enigma incontornável da subjetividade. Noutras palavras, o hiato que, separando-me do exterior, separa-me de mim mesmo. Tal incapacidade de se ver de fora parece implicar uma deficiência ou uma fratura do próprio ser. Ser assim é também uma maneira de não ser.

Bento Prado Jr.

Qual é, pois, esse outro a quem sou mais apegado do que a mim, já que, no seio mais consentido de minha identidade comigo mesmo, é ele que me agita?

Jacques Lacan

\section{INTRODUÇÃO}

Propor, atualmente, um trabalho sobre a Fenomenologia do Espirito exige, de fato, algumas palavras de explicação. Sem o pecado da autocondescendência, é perceptível como essas páginas foram sendo decantadas na filosofia contemporânea, até o momento em

1 Graduando em Filosofia na USP. Bolsista FAPESP (processo 18/17008-8).

marcus.felizardo@gmail.com 
que, atualmente, outros momentos da obra de Hegel são vistos como mais profícuos. À parte as lamentações, aqui estamos longe de uma pretensiosa tentativa de salvá-la; na verdade, no presente trabalho, trata-se de explicitar, dentro do itinerário hegeliano e através de um rompimento com a filosofia anterior, a centralidade da categoria de desejo para a compreensão de movimentos maiores da filosofia hegeliana.

Assim, no item 2 trataremos das relações entre Hegel e a filosofia kantiana, e como nosso autor parte de problemas legados pela filosofia crítica, sobretudo em relação ao papel da noção de apercepção. Na parte 3 aprofundaremos a questão, evidenciando como Hegel subverte o cogito moderno e estabelece outra relação da subjetividade consigo mesma. $\mathrm{Na}$ derradeira, o item 4, a questão será a noção de Espírito e como ela pode ser vista como mais um ponto de inflexão da filosofia hegeliana em relação ao que era feito até então.

\section{2 ÀS VOLTAS COM O KANTISMO}

Para Hegel, a modernidade é a época das separações: sujeito e objeto, razão e sen sibilidade, espírito e natureza, liberdade e necessidade, etc., sendo que Kant seria a expressão maior dessas distinçôes, dos tempos modernos naquilo que eles possuem de fragmentado, em que os indivíduos são separados, cortados em suas relações com o mundo ${ }^{2}$. A tarefa da filosofia, nesse caso, seria a união dessas cisões, "suprimir (aufzubeben) tais opostos (Gegensätze) tornados fixos” (HEGEL, 1986a, p. 21; 2003 p. 38).

Partindo dessa questão, não é à toa que a Fenomenologia do Espirito comece, em sua introdução ${ }^{3}$, por um confronto com as idiossincrasias da filosofia kantiana, denominada, entre outras alcunhas, de "consciência natural" - como questiona Paulo Arantes, "que outra filosofia maltratara tanto as certezas da 'consciência natural' (entendamos: literalmente inculta, pobre de espírito; mas também: esclarecida apenas pela luz natural da simples razão) quanto a especulação hegeliana?” (ARANTES, 1996, p. 213). Lembremos como, de fato, se inicia a obra, já que o prefácio foi escrito posteriormente: "É uma representação natural que a filosofia, antes de abordar a Coisa mesma - ou seja, o conhecimento efetivo do que é, em verda -

2 Uma boa análise da maneira como Hegel compreende a modernidade encontramos nos dois primeiros capítulos de HABERMAS (2000).

3 Sobretudo dos parágrafos 73 a 76. Para uma análise detida da introdução da Fenomenologia do Espíri to, cf. BOURGEOIS (1997); também HABERMAS (2014, cap. I); e, por fim, NOBRE (2018). 
de -, necessita primeiro entender-se sobre o conhecer, o qual se considera ou um instrumento com que se domina o absoluto, ou um meio através do qual o absoluto é contemplado" ${ }^{4}($ HEGEL, 2014, p. 69, §73). O termo “representação" tem uma significação sui generis na prosa hegeliana, herdada principalmente do cartesianismo e do idealismo alemão e que no mais das vezes é pejorativa ${ }^{5}$, isto é, as representações, ao fixarem significações que estabelecem uma identidade do objeto avessa ao dinamismo e às mediações de qualquer tipo, ganham na obra hegeliana um sentido específico: onde há representação, não há propriamente ainda dialética, já que o trabalho do negativo, trabalho da dialética, é fazer com que essas representaçóes fixas passem a sofrer uma espécie de curto-circuito em que aquilo que é inicialmente negado, em seguida adquira papel essencial.

Bom, esse ponto de partida e, ao mesmo tempo, objeto de crítica, dá o tom das ambiguidades presentes na relação entre Hegel e Kant; porém, no que tange o tema do presente trabalho, é inegável o olhar negativo que nosso autor dirige a certos enunciados de seu predecessor - apesar da inegável influência da filosofia kantiana para absolutamente tudo que sobreveio posteriormente em matéria filosófica —, sobretudo, como afirma Robert Pippin, acerca da "compreensão de Kant do que este chamou de princípio fundamental de toda a sua filosofia teórica, a unidade transcendental da apercep̧ão e o uso desse princípio na justificação dos conhecimentos sintéticos a priori” (PIPPIN, 1989, p. 17).

No percurso da Fenomenologia, nosso autor identifica certos pressupostos na filosofia kantiana que não passaram devidamente pelo tribunal da razão, embora Kant afirme a necessidade de nada deixar passar sem o crivo da crítica. Um desses pressupostos é o de que há identidade do sujeito independentemente de sua atividade, isto é, o sujeito se "conserva" não importando aquilo com que é identificado. A ideia kantiana de "eu transcendental" trata exatamente disso: o "Eu penso", que acompanha todas as representaçóes do sujeito e sem o qual não é possível afirmar que elas são dele, significa pensar um Eu sempre idêntico a si mesmo e sempre diferente daquilo que está representando. No $\$ 16$ da Crítica da Razão Pura temos a exata dimensão do que está em jogo:

O eu penso tem de poder acompanhar todas as minhas representaçóes; pois, do contrário, seria em mim representado algo que não pode ser pensado de modo al-

$4 \quad$ Grande parte das traduções da Fenomenologia do Espírito que aqui se encontram foram modificadas com base nos apontamentos em aula do prof. Luiz Sérgio Repa, a quem muito agradeço.

5 Para um aprofundamento da questão e contraponto à posição hegeliana, cf. LEBRUN (2006b, p. 509). 


\begin{abstract}
gum, o que significa simplesmente que: ou a representação seria impossível, ou ao menos não seria nada para mim [...] Todo diverso da intuição, portanto, tem uma relação necessária com o eu penso no mesmo sujeito em que esse diverso é encontrado [...] pois do contrário eu teria um "eu" tão multicolorido e diverso quantas são as representações que tenho e das quais sou consciente (KANT, 2013, pp. 129131).
\end{abstract}

Nesse momento, Kant enfatiza que a consciência-de-si (selbstbewusstsein) enquanto originária e sempre idêntica a si mesma, é a condição de toda representação da objetividade e da aplicação das categorias à intuição; assim, sem o eu penso não é possível conhecer, porque não poderíamos supor que o diverso dado pela sensibilidade poderia ter um sentido de representação no sujeito, isto é, sem esse eu originário, haveria uma dispersão em infinitos “eu's", que seriam distintos a cada instante, impossibilitando o conhecimento, porque não haveria síntese. Consequentemente, mesmo que "a unidade da consciência-de-si possa ser concebida somente no andamento da investigação", ainda assim, "já no seu início a identidade do Eu precisa ser levada em conta” (HABERMAS, 2014, p. 44).

Do ponto de vista hegeliano, ao mesmo tempo em que vemos a cisão de uma época sendo escancarada, o caminho se abre, também, para a subversão desse princípio de identidade, que salta mediações e alça, como meramente pressuposta, a identidade do Eu consigo mesmo ao posto de condição sine qua non para toda e qualquer forma de conhecimento possível; trata-se, portanto, como afirma Habermas, da "suposição de um sujeito de conhecimento pronto ou, dito de outro modo, um conceito normativo de Eu" (Idem). Bom, nada poderia ser mais oposto ao projeto fenomenológico hegeliano do que essa espécie de "entificação de princípios de formais de identidade e unidade" (SAFATLE, 2012, p. 23).

Por isso, também, que nosso autor pode criticar Kant por um suposto "psicologismo subjetivista” (McDOWELL, 2009, p. 76), porque, do ponto de vista hegeliano, não é possível imaginar que a estrutura do conhecimento se passe no interior de um mundo de fenômenos, em que as coisas seriam dotadas de um em-si absolutamente exterior ao âmbito da experiência. Desse ângulo, os conceitos, e em última instância os sujeitos, não se modificariam, pois não seriam tocados pela experiência real. Diante desse quadro, ele pôde muito tranquilamente afirmar que Kant, ao elogiar a lógica por não ter, aparentemente, se modificado, o que indicaria um "caminho seguro" (KANT, 2013, BVIII, p. 25), seria algo totalmente equivocado do ponto de vista de uma filosofia realmente crítica, pois essa inércia indicaria, na ver dade, uma necessidade de "uma total reelaboração; pois um labor contínuo de dois mil anos do espírito deve ter-lhe proporcionado uma consciência mais elevada sobre seu pensar e sua essencialidade pura em si mesma” (HEGEL, 2016, p. 54); trata-se, em última instância, da im- 
posição de um modo de existência natural, tendo em vista, por exemplo, o princípio de não contradição, que rege nosso pensar em sua integralidade, e que impediria, para Hegel, a emergência de um sujeito que se confronte com a ruína interna à representação como organizadora do nosso modo de pensar.

Assim, o que, de fato, significa pensar a identidade do sujeito, da consciência-desi, como algo que não poderia ser tocado pelo movimento das coisas, pelos objetos? Uma identidade dada de antemão, confortável no porto seguro de uma lógica milenar. Por isso, nosso autor estabelecerá outro tipo de relação com a consciência-de-si; para Hegel, ela precisa se provar como idêntica a si mesma - a identidade hegeliana é fruto de uma construção - e só pode provar isso em uma relação prática com a objetividade, com o real, que assume forma negativa. Dessa forma, para alcançar a identidade ela precisa se imbricar com os objetos, se relacionar com eles, diferentemente do modelo kantiano, em que havia um fosso que separava o sujeito da experiência da objetividade.

Ora, essa negatividade que, na história da filosofia, nunca teve real direito de se impor, encontra aqui um lugar próprio - a negatividade é, inclusive, elemento central à constituição do Espírito: "O espírito só alcança sua verdade na medida em que se encontra a si mesmo no dilaceramento absoluto. Ele não é essa potência como o positivo que se afasta do negativo [...] Ao contrário, o espírito só é essa potência enquanto encara diretamente o negativo e se demora junto dele” (HEGEL, 2014, p. 41). Assim, a tarefa que, de certo modo, nosso autor propõe, é subverter alguns pressupostos da filosofia clássica, que, como nos diz Gérard Lebrun, sempre "pode falar do negativo, sem nunca lhe conceder presença, citá-lo sem fazer que apareça” (LEBRUN, 2006a, p. 275); por isso, em Hegel, trata-se de integrar a negatividade no interior daquela unidade originária que dá sentido ao mundo e às coisas, rompendo com a velha forma de lidar com o negativo, que durante muito tempo designou "uma ausência que bem se pode localizar o quanto se quiser e onde se quiser, mas que nunca advém" (Idem). Dessa forma, a consciência-de-si se torna o lugar privilegiado de uma experiência fundamental de negatividade, manifestada, em sua relação aos objetos, sob a forma do desejo (begiarde). No entanto, o que exatamente significa a negatividade do desejo nesse contexto? 
se manifesta de uma maneira particularmente clara na substituição do eu penso de Descartes pelo eu desejo. (KOJÈVE, apud AUFFRET 1990, p. 47).

O desejo tem como característica fundamental uma negatividade que lhe é interna, e quando falamos em negatividade estamos lidando com uma referência ao objeto que se dá, ao mesmo tempo, na intenção de aniquilá-lo, e, também, na intenção de suprir "sua própria falta, sua própria unilateralidade” (HEGEL, 1995b, p. 198) - na juventude, à lá antropologização filosófica kojèviana, Hegel metaforiza a "humanidade" como sendo "esta noite, este nada vazio que, em sua simplicidade, contém tudo, uma profusão de representaçóes infinitamente múltiplas, imagens, das quais nenhuma lhe ocorre de pronto" (HEGEL, 2015, p. 175) - falta de si para si a partir da presença do Outro. Falta à consciência-de-si a verdade da certeza de si mesma, e dessa forma, o desejo se constitui como uma ação negativa de destruição da alteridade e satisfação dessa falta; é, assim, essencialmente um "nada revelado, um vazio irreal” (KOJÈVE, 2014, p. 12). Ele deve ser entendido como a própria consciência-de-si, não à toa Hegel diz que ela "é desejo, em geral" (HEGEL, 2014, p. 136). Não se trata de compreendê-lo como uma espécie de instrumento, ou ação indireta, da consciência para suprimir aquilo que a confronta, pois isso seria ignorar o papel fundante que o desejo desempenha para a própria consciência-de-si e impediria que a subjetividade fosse pensada diferentemente dos moldes kantianos; desse modo, devemos pensar essa consciência desejante também como um vazio, como uma ação negadora que tenta anular o objeto para transformá-lo e, simultaneamente, mudar a si mesma. Trata-se de algo bem-visto por Alexandre Kojève, aquele responsável por reintroduzir o hegelianismo na França para toda uma geração de intelectuais ${ }^{6}$ : "o Eu do desejo é um vazio que só recebe um conteúdo positivo real pela ação negadora que satisfaz o desejo ao destruir, transformar e assimilar o não-Eu desejado” (KOJÈVE, 2014, p. 12).

Por ser o Eu um vazio sem determinação, que apenas recebe conteúdo pela negação que satisfaz sua falta, é importante notar como o objeto aparece como aquilo que é essencial à constituição do Eu; está posta aí a primeira forma de uma contradição que se mostrará insustentável: a essência da consciência-de-si está fora dela. Esse momento de saída de si posteriormente se mostrará fundamental para que haja um retorno que incorpore essa negatividade. Bem, trata-se de algo compreendido por Adorno a respeito da dialética hegeliana: "Hegel se curva em toda parte à essência própria do objeto, em toda parte o objeto é renovadamente

6 Para uma melhor caracterização da leitura, e seus problemas, que Kojève faz de Hegel, e da influência que ele exerceu no meio francês, cf. ARANTES (1991); DESCOMBES (1979); JARCZYK, G et LABARRIÈRE, P-J, (1996). 
imediato, mas mesmo essa subordinação à disciplina da coisa exige o mais extremo esforço do conceito. A disciplina da coisa triunfa no momento em que as intençôes do sujeito se desfazem no objeto” (ADORNO, 2013, p. 78). Essa disciplina própria à objetividade é um elemento central para a compreensão de um sujeito marcado por uma não-identidade interna.

No início do capítulo IV, Hegel é taxativo: para que a consciência-de-si seja, é preciso que a diferença tenha a forma do ser, isto é, é necessário que haja, realmente, uma alteridade no mundo sensível, e este, Hegel afirma ser para ela "um subsistir, mas que é apenas fenômeno, ou diferença que não tem em si nenhum ser” (HEGEL, 2014, p. 136). Então, enquanto o mundo sensível for para ela apenas mero fenômeno, ela própria será “apenas a tautologia sem movimento do Eu sou Eu” (Idem). Esse passo além, em direção a um processo de transformação e saída do solipsismo, é essencial, porque, como diz Hegel, a verdade da consciência-de-si é a "unidade da consciência-de-si consigo mesma” (Idem). Como afirma Hyppolite, "quando se considera somente a abstração do $\mathrm{Eu}=\mathrm{Eu}$, obtém-se somente uma tautologia inerte. O movimento da consciência de si, sem o qual ela não seria, exige, portanto, a alteridade, esse mundo da consciência que, assim, é conservado para a consciência de si. É conservado, porém, não mais como ser-em-si, objeto que reflete passivamente a consciência, mas como objeto negativo, que deve ser negado a fim de que a consciência de si estabeleça, na negação do ser-outro, sua própria unidade consigo mesma” (HYPPOLITE, 1999, p. 173). Esse momento de negação, como vimos, é o desejo.

Sendo assim, o que está em jogo é a oposição entre a autoafirmação do Eu como essencial e, no entanto, a mediação pela alteridade do mundo sensível, essa presença que há de ser liquidada para que ele possa se afirmar como idêntico; essa contradição entre dependência e independência não pode integrá-la, deve ser superada na devastação do objeto, mostrando que o objeto não é nada, que "é marcado para ela com o sinal do negativo" (HEGEL, 2014, p. 136). Assim, o sujeito, que marca seus objetos com esta negatividade do desejo, impedindo qualquer determinação de perdurar no campo fenomênico, é, de fato, um “vir-a-ser” constante, está sempre em uma espécie de não-identidade consigo mesmo, tentando adequar-se a si a partir do oposto. Eis aqui a primeira dialética do desejo: “[...] a consciência-de-si é desejo. Certa da nulidade desse Outro, póe para si tal nulidade como sua verdade; aniquila o objeto independente, e se outorga, com isso, a certeza de si mesma como verdadeira certeza, como uma certeza que lhe veio-a-ser de maneira objetiva” (HEGEL, 2014, p. 140). 
Contudo, como em todo o caminho da Fenomenologia, a consciência-de-si vai experimentar a frustração na realização de seu próprio conceito ${ }^{7}$; como afirma Hegel, "a consciência-de-si não pode assim suprimir (aufzubeben) o objeto através de sua relação negativa para com ele; pelo contrário, ela o reproduz por isso, assim como o desejo” (Idem, p. 140). O caminho é bloqueado, pois ela nunca consegue dar ao mundo exterior sua própria face, há infinitos objetos que lhe confrontam incessantemente, e por isso ela entra em um processo de repetição infinita. Nesta segunda dialética do desejo, no mesmo instante que satisfaz seu desejo, suprimindo o objeto, imediatamente surgem outro desejo e outro objeto: o sujeito, de fato, nunca se alcança, e a identidade consigo mesmo dura apenas o instante de supressão do objeto, que uma vez consumido, dá lugar à incerteza de si mesmo.

O desejo, portanto, é reiterativo, permanece no mesmo ciclo de consumo e reprodução, se afirmando indefinidamente, pois não há nenhuma instância que estabilize a identidade da consciência-de-si, nenhum lugar em que ela possa, realmente, apoiar a identidade que está buscando afirmar, porque se depara com o nada do objeto, que se esvaiu e se esvai a cada vez.

Para entender melhor esse ponto, devemos diferenciar dois tipos de negação dialética: a umschlagen e a Aufhebung ${ }^{8}$. A umschlagen consiste em uma passagem no oposto, no "desaparecer incessante dos contrapostos dentro deles mesmos" (HEGEL, 2017, p. 80), em que um termo intervém pondo sua essencialidade no outro; como sabemos, na Fenomenologia são extremamente comuns situaçôes em que a consciência se encontra nessa espécie de movimento pendular. É desse tipo de negação que estamos tratando nesse momento em que a consciência-de-si se vê reiterando seu próprio desejo e, por consequência, também o objeto. Falta, portanto, o momento da segunda forma de negação dialética: a Aufhebung; nela, o movimento constante de passagem no oposto se interrompe, pois há uma internalização da oposição. A Aufhebung é, de certa forma, uma realização da contradição, pois é uma negação que conserva, ou seja, ao superar a oposição, aquilo que foi negado se conserva em uma nova determinação, pois "o que se supera (aufhebt), não se torna, por isso, nada [...], algo superado (Aufgehobenes), ao contrário, é algo mediado, é aquilo que não é, mas como resultado que par-

7 Esse é um dos dados substanciais da filosofia hegeliana, pois esse fracasso, posteriormente, se transmutará em necessidade do Espírito; é como se as frustrações da consciência fossem contingências que lhe acometem, mas é através do acúmulo delas que o caminho do Espírito se traça.

8 Umschlagen é comumente traduzido para o português como interversão, e Aufhebung por suprassunção - no caso do segundo termo, em muitos casos no presente projeto, e mesmo agradecendo a sugestão do pa recerista por "ultrapassar", escolhemos traduzi-lo por superar. 
tiu de um ser; ele tem, portanto, ainda em si, a determinidade da qual provém” (HEGEL, 2016, p. 111).

Por isso, para que esse processo ao infinito acabe, o objeto precisa ser "em si mes mo negação” e, também, “ao mesmo tempo independente” (HEGEL, 2014, p. 141), isto é, ao ser negado ele precisa se preservar no ser para, desse modo, conferir objetividade à certeza do Eu. É preciso que o objeto se prolongue no tempo, que seja, de algum modo, independente, no sentido de um ser vivo que subsiste. Ora, o único objeto que pode realizar isso é uma outra consciência-de-si; por esse motivo, na terceira dialética do desejo, vem à tona a enfática frase de Hegel, "a consciência-de-si só alcança sua satisfação em uma outra consciência-de-si” (Idem): o Eu só se satisfaz em outro Eu.

Uma consciência-de-si deve sinalizar, de algum modo, sua absolutidade, enquanto a outra é posta como nula, mas sem morrer de fato; o nome dessa autonegação é o que Hegel chama de reconbecimento (anerkennung). A primeira significação que esse conceito porta é negativa: alguém que reconhece o Outro, de certo modo, está negando a si para pôr o Outro como valor supremo, porque só uma pode ser absoluta. Para a consciência-de-si o reconhecimento vai funcionar como um desdobramento do desejo, isto é, ela não deseja mais consumir o objeto natural, agora deseja que ele a afirme. Há uma passagem crucial do texto de Kojève, que é significativa para essa questão, e que, inclusive, aborda alguns aspectos centrais da luta por reconbecimento:

\footnotetext{
"O homem se confirma como humano ao arriscar a vida para satisfazer seu desejo humano, isto é, seu desejo que busca outro desejo [...] Desejar o desejo do outro é, em última análise, desejar que o valor que eu sou ou que eu represento seja o valor desejado por esse outro: quero que ele reconheça meu valor como seu valor, quero que me reconheça como um valor autônomo. Isto é, todo desejo humano, antropogênico, gerador de consciência-de-si, da realidade humana é, afinal, função do desejo de reconhecimento" (KOJÈVE, 2014, p. 14).
}

Com esse raciocínio, o russo decifra a transformação no desejo, que anteriormente era o desejo do animal, mas agora se transforma, de certo modo, em um desejo eminente mente humano, sendo que para ele só há, verdadeiramente, "homem”, quando ele deseja ser desejado - usar termos como "homem" ou "humano" nesse contexto pode parecer, mas não é, nada óbvio: o salto interpretativo de Kojève consiste em transformar a Fenomenologia do Espirito em uma “antropogênese”, isto é, em enxergar nela uma descrição do nascimento e desenvolvimento da espécie humana, e por isto, para ele, neste momento da obra, nasceria a própria ideia de homem. Sobre as habilidades interpretativas de Kojève, Paulo Arantes diz: "De 
curtos-circuitos em recobrimentos inesperados, Kojève ia assim impregnando o mundo de hegelianismo graças um enorme talento de narrador, louvado em todos os testemunhos a seu respeito. Introduzindo personagens pitorescos na galeria das figuras hegelianas, dramatizadas nesse meio tempo, revertendo situaçóes em cenas que se sucedem com velocidade teatral, Kojève acabou transformando a austera Fenomenologia num folhetim onde se narra a gênese do mundo moderno" (ARANTES, 1991, p. 74). Ao fim, Kojève é bem-sucedido na tentativa de expor a diferença fundamental entre o desejo humano e o desejo animal: o animal deseja o ser e se satisfaz com ele, não transcende esse natural que é negado abstratamente; já o homem não deseja uma coisa, mas, sim, outro desejo: "o desejo humano, ou melhor, antropogênico [...] difere portanto do desejo animal [...] pelo fato de buscar não um objeto real, positivo, dado, mas um outro desejo” (KOJÈVE, 2014, p. 13).

\section{A EMERGÊNCIA DO ESPÍRITO}

Dessa forma, esse desejo duplicado é intrinsecamente social, já que o objeto do desejo só vale na medida em que é valorizado ou reconhecido por um Outro. Na primeira forma do desejo o Eu já revelava seu verdadeiro caráter, um não-ser que é pura ação de negar, mas ainda no nível da animalidade, porque a negação do desejo é condicionada ao objeto natural; mas, como o desejo se duplica nessas duas instâncias, desejo do desejo, no sentido de querer algo porque esse algo é também caro ao Outro, temos uma relação desiderativa humana: desejar um desejo é querer que o valor desejado pelo outro seja o valor representado por si mesmo. Aí percebemos onde o desejo de reconhecimento desembocará mais à frente, em uma luta, chamada por Kojève de "puro prestígio" (KOJÈVE, 2014, p. 14), em que a consciência arrisca a vida para provar que sua essência "não é o ser [...] nem o seu submergir-se na expansão da vida” (HEGEL, 2014, p. 145), isto é, trata-se de ser reconhecida enquanto pura negatividade livre de qualquer forma de determinação.

Esse livrar-se de toda aderência renova a maneira como enxergamos a ideia de subjetividade, pois é perceptível como a concepção de sujeito que, através dessa teoria do desejo que Hegel nos fornece, poderia ser caracterizada por um sujeito não substancial, distante de qualquer tipo de essencialização - "segundo minha concepção - que só deve ser justificada pela apresentação do próprio sistema —, tudo decorre de entender e exprimir o verdadeiro não como substância, mas também, precisamente, como sujeito" (HEGEL, 2014, p. 32). A subjetividade passa a ser marcada por uma atividade que se dá pelo enredamento com certas 
experiências de heteronomia fundamentais à formação, sobretudo quando a consciência percebe a gênese social de seus próprios pressupostos e que seu desejo é desejo de um Outro. A identidade desse sujeito estruturalmente distinto da filosofia da subjetividade anterior, também sofre uma metamorfose: antes era manifestada através da ideia de que só é possível pensar algo a partir de operaçốes de unidade e estabilidade — como em Kant —, em que o imutável é intrinsecamente mais valoroso do que o transitório, marcado por uma indeterminação imanente, e agora passa a ser, fundamentalmente, concebida como "algo negativo; contudo, não é o nada vazio e abstrato em geral, mas é a negação do ser e de suas determinações. Porém, como tal, a identidade é ao mesmo tempo relação; e na verdade relação negativa para consigo mes ma, ou diferença dela consigo mesma” (HEGEL, 1995a, p. 230).

Desse modo, o próprio conceito de "Eu” só é alcançável, de maneira duradoura e objetiva, por meio de um outro Eu; a certeza de si inicial, sempre precária, só pode dar lugar a um conhecimento verdadeiro sobre a subjetividade se tem por objeto uma outra subjetividade, ou seja, se ela se vê fora de si na forma do ser, e não apenas na posição epistemológica do objeto de uma consciência-de-si solitária, que se refere a si mesma como única condição de representação de objeto; nessa posição epistemológica, o Eu, diz Hegel, "não é de fato objeto" (HEGEL, 2014, p. 142), pois dizer que o Eu é objeto quando ele ainda é simplesmente objeto para uma consciência-de-si isolada, não é de fato pensá-lo como uma instância objetiva.

Aqui está uma das grandes guinadas na filosofia do sujeito que Hegel realiza, porque, a partir de agora, para chegarmos à consciência-de-si, é necessário perceber que o "si” não está dentro, mas fora; ora, mas para estar fora, nesse contexto, é preciso que seja um outro, logo, o ser do Eu depende de um Outro. A consciência-de-si exige que esse "si”, sua instância reflexiva em movimento, seja posto para fora, mas ele só pode ser posto para fora se, de fato, há um Outro que se põe para ela. Imediatamente com isso, Hegel diz que "para nós, portanto, já está presente o conceito de Espírito (geist)” (Idem); quando uma consciência-de-si só é por meio de uma outra consciência-de-si, nós temos o conceito de Espírito, um "Eu que é Nós, Nós que é Eu” (Idem). Essa é a primeira grande determinação do conceito de Espírito, ele é formado por consciências-de-si em relação.

E neste conceito de Espírito há, manifestadamente, uma inversão do que era o ponto de partida da filosofia do sujeito até então, isto é, se começava pelos indivíduos isolados, e a partir desse ponto arquimediano passava-se à especulação sobre como os vínculos supraindividuais se estabelecem. Contudo, a filosofia hegeliana inverte esse modelo, partindo propriamente das relaçóes, entendendo-as como o que há de mais tangível, pois especular a ideia de sujeito através de processos de autoidentidade não passa de uma abstração que deve ser supe- 
rada, e essa inversão será fundamental para a afirmação das relações como o elemento originá rio, em que a consciência descobrirá os pressupostos sociais no interior daquilo que lhe aparece como representação natural; e se é assim, se as relações são primeiras e pressupostas, a ques tão é como elas são postas ${ }^{9}$, ou seja, como são reconhecidas, e que tipo de transfiguração ocorre no campo da experiência quando elas são reconhecidas, porque na dialética hegeliana é patente como no momento em que esse movimento de explicitação de determinações outrora falsamente "bem-conhecidas" é efetivado, novos efeitos na dimensão da existência são produzidos, afinal, "o bem-conhecido em geral, justamente por ser bem-conhecido, não é reconhecido" (HEGEL, 2014, p. 40). em-si”, cf. HEGEL (2016, p. 127). 


\section{REFERÊNCIAS BIBLIOGRÁFICAS}

ADORNO, T. Três estudos sobre Hegel. São Paulo: UNESP, 2013.

ARANTES, P. Ressentimento da dialética. São Paulo: Paz e Terra, 1996.

ARANTES, P. Um Hegel errado mas vivo. Revista Ide, São Paulo, n. 21, 1991.

AUFFRET, D. Alexandre Kojève, la philosophie, l'État, le fin de l'histoire. Paris: Grasset, 1990.

BOURGEOIS, B. Préface et introduction de la Phénoménologie de l'Esprit. Paris: Vrin, 1997.

DESCOMBES, V. Le même et l'autre: 45 ans de philosophie française. Paris: Seuil, 1979

KANT, I. Crítica da Razão Pura. Petrópolis: Vozes, 2013.

HABERMAS, J. Conhecimento e interesse. São Paulo: UNESP, 2014

HABERMAS, J. O discurso filosófico da modernidade. São Paulo: Martins Fontes, 2000.

HEGEL, G. Werke 2. Jenaer Schriften (1801-1807). Frankfurt am Main: Suhrkamp, 1986a

HEGEL, G. Diferença entre os sistemas filosóficos de Fichte e de Schelling. Lisboa: Imprensa Nacional, 2003.

HEGEL, G. Ciência da lógica: 1. A Doutrina do Ser. Petrópolis: Vozes, 2016

HEGEL, G. Ciência da lógica: 2. A Doutrina da Essência. Petrópolis: Vozes, 2017.

HEGEL, G. Fenomenologia do Espirito. Petrópolis, RJ: Vozes, Bragança Paulista: Editora Universitária São Francisco, 2014.

HEGEL, G. Enciclopédia das Ciências Filosóficas, vol. I. São Paulo: Loyola, 1995 a. 
HEGEL, G. Enciclopédia das Ciências Filosóficas, vol. III. São Paulo: Loyola, 1995 b.

HEGEL, G. Preleções sobre a Filosofia do Espírito (1805/1806). Primeira parte: "O Espírito segundo seu conceito". Tradução Erick Lima. Revista de Filosofia Moderna e Contemporânea. Brasilia, v. 3, n. 2, 2015.

HYPPOLITE, J. Gênese e estrutura da Fenomenologia do Espirito de Hegel. São Paulo: Discurso Editorial, 1999.

JARCZYK, G; LABARRIÈRE, P-J. De Kojève à Hegel: cent cinquante ans de pensée hégélienne en France. Paris: Albin Michel, 1996.

KOJÈVE, A. Introdução à leitura de Hegel. Rio de Janeiro: Contraponto, 2014.

LEBRUN, G. A paciência do conceito: ensaio sobre o discurso hegeliano. São Paulo: UNESP, $2006 a$.

LEBRUN, G. A filosofia e sua história. São Paulo: Cosac Naify, 2006b.

McDOWELL, J. Having the World in View: Essays on Kant, Hegel and Sellars. Cambridge: Harvard University Press, 2009

NOBRE, M. Como nasce o novo. São Paulo: Todavia, 2018.

PIPPIN, R. Hegel's Idealism. The Satisfactions of Self-Consciousness. Cambridge: University Press, 1989.

PRADO JR, B. Alguns Ensaios. São Paulo: Paz e Terra, 2000.

SAFATLE, V. Grande Hotel Abismo: para uma reconstrução da teoria do reconhecimento. São Paulo: Martins Fontes, 2012. 